\title{
Qualidade de ovos de galinha comercializados em Barreiras, BA, estocados em diferentes condições de temperatura
}

\author{
Quality of chicken eggs sold in Barreiras, Bahia, \\ stored under different temperatures
}

Danilo Gusmão de Quadros ${ }^{[a]}$, Thiago Ribeiro de Jesus ${ }^{[b]}$, Carlos Hideo Kanematsu卢, Alberto Magalhães de Sá ${ }^{[b]}$, Guilherme Augusto Vieira da Silva ${ }^{[c]}$,Anderson Luiz Rocha da Silva ${ }^{[d]}$, Alexandro Pereira Andrade ${ }^{[e]}$

[a] Engenheiro agrônomo, DSc., professor da Faculdade de Agronomia, Universidade do Estado da Bahia (UNEB), Barreiras, BA Brasil, e-mail: uneb_neppa@yahoo.com.br

[b] Acadêmicos da Faculdade de Agronomia Universidade do Estado da Bahia (UNEB), Barreiras, BA - Brasil, e-mails: uneb_neppa@yahoo.com.br; albert_osa@hotmail.com

[c] Médico-Veterinário, MSc., professor da Faculdade de Ciências Agrárias e da Saúde (UNIME-BA), Salvador, BA - Brasil, e-mail: gavet@uol.com.br

[d] Zootecnista pela Universidade Estadual do Sudoeste da Bahia (UESB), Vitória da Conquista, BA - Brasil, e-mail: uneb_neppa@yahoo.com.br

[e] Engenheiro agrônomo, MSc., doutorando em Zootecnia na Universidade do Estado da Bahia, (UESB), Itapetinga, BA - Brasil, e-mail: uneb_alex@yahoo.com.br

\section{Resumo}

O objetivo deste trabalho foi avaliar a qualidade interna de ovos vermelhos de galinha de granja comercial e de tipo caipira, mantidos sob diferentes condições de refrigeração e comercializados em supermercados, mercados de bairros e na feira livre de Barreiras, Bahia. Foram adquiridos, semanalmente (sempre no mesmo dia), 60 ovos, simulando um consumidor padrão, sendo 24 ovos vermelhos de granja comercial de dois supermercados, 24 ovos vermelhos de granja comercial de dois mercados de bairro e 12 ovos tipo caipira da feira livre. Os ovos obtidos nos diferentes estabelecimentos foram estocados sob refrigeração no fundo e na porta de um refrigerador doméstico e em temperatura ambiente. A avaliação da qualidade dos ovos foi realizada pelas determinações de peso médio do ovo, altura de albúmen, unidade Haugh, percentual do albúmen e da gema. Os dados foram submetidos à análise de variância segundo delineamento inteiramente casualizado, considerando como significativos os valores da probabilidade do valor de F menor que $5 \%$. Com base na qualidade interna dos ovos, concluiu-se que os mercadinhos foram os locais com a menor qualidade dos ovos comercializados, enquanto os supermercados e a feira livre mostraram maior qualidade. 0 ambiente refrigerado mostrou-se como o local mais adequado para a manutenção da qualidade de ovos armazenados por um período de até 14 dias.

Palavras-chave: Albúmen. Comercialização. Unidade Haugh. 


\section{Abstract}

The objective of this study was to evaluate the quality of eggs originated from commercial farms and home raised layers, which are sold in supermarkets, small grocery stores and street markets in the city of Barreiras, Bahia. These eggs were maintained under different storage conditions and the effect of temperature on the quality of these products was also evaluated. Sixty eggs were purchased per week on the same weekday, simulating a normal customer behavior: 24 were brown eggs from commercial farms purchased in two different supermarkets; 24 were brown eggs from commercial farms purchased in two smaller grocery stores; and 12 were brown eggs from home raised layers purchased at a local street market. The eggs obtained from the different stores were subjected to three regular household storage conditions: back of a refrigerator; refrigerator's door; or at room temperature. The eggs were assessed for average egg weight, albumen height, Haugh unit, and percentage of albumen and yolk. The data were subjected to analysis of variance in a completely randomized design, and F-values lower than $5 \%$ were considered statistically significant. Based on the analysis of internal egg quality, it was concluded that the lowest quality eggs were those purchased in small grocery stores and the best were bought in supermarkets and in the local street market. The refrigerator is the best place to store eggs during periods up to14 days.

Keywords: Albumen. Egg commercialization. Haugh unit.

\section{Introdução}

Os ovos consumidos no mundo são normalmente obtidos de galinhas (Gallus domesticus) selecionadas para a postura. 0 ovo é um dos alimentos mais completos, composto por proteínas, glicídios, lipídios, vitaminas, minerais e ácidos graxos essenciais (AUSTIC; NESHEIM, 1990). Além ser um alimento completo e equilibrado em nutrientes, é uma fonte de proteína de baixo valor econômico, podendo contribuir para melhorar a dieta de famílias de baixa renda (LEANDRO et al., 2005).

A evolução do consumo de ovos no Brasil não tem acompanhado o aumento do consumo de carnes, tendo apresentado incremento muito baixo, mesmo considerando-se que a proteína do ovo apresenta excelente valor biológico, menor preço e que a grande maioria da população brasileira sofre deficiência nutricional (BERTECHINI, 2003).

As condições de armazenamento de ovos, como o tempo e a temperatura, têm importância fundamental na manifestação da capacidade de formação de espuma, essencial para a boa qualidade sensorial, particularmente de textura. Por terem seus constituintes naturalmente protegidos pela casca, a qualidade do albúmen se torna notória somente quando o comprador for utilizá-los na obtenção de emulsões tipo: merengue e "musse" (SMITH; NGUYEN, 1984).

Selecionar parâmetros para analisar as mudanças na qualidade do ovo implica em considerar as exigências relacionadas à qualidade por parte dos produtores, consumidores e processadores de ovos. Para os produtores, a qualidade está relacionada com o peso do ovo e a resistência da casca (como defeitos, sujidades, quebras e manchas de sangue). Para os consumidores, a qualidade está relacionada com o prazo de validade do produto e com as características sensoriais, como cor da gema e da casca (ALLEONI; ANTUNES, 2001). Para os processadores (fábricas de alimentos), a qualidade está relacionada à facilidade da retirada da casca, com a separação da gema e da clara, com as propriedades funcionais tecnológicas e com a cor da gema (especialmente para massas e produtos de padaria) (ROSSI; POMPEI, 1995).

Existem cinco métodos para estimar a qualidade de ovos abertos, com bases quantitativas, relacionadas ao albúmen: altura da clara (WILGUS; WAGENEN, 1936); índice do albúmen (HEIMAN; CARVER, 1936); índice da área do albúmen (PARSONS; MINK, 1937); percentagem da clara espessa e fina (HOLTS; ALMIQUIST, 1932) e a unidade Haugh (HAUGH, 1937).

O uso da unidade Haugh tem sido aceito como uma medida da qualidade do albúmen em diversas pesquisas sobre a qualidade de ovos (EISEN et al., 1962). Apesar das críticas, ela é considerada uma medida padrão de qualidade e empregada por toda a indústria avícola (WILLIAMS, 1992). As críticas a respeito da unidade Haugh são baseadas, essencialmente, na correção do peso do ovo (ALLEONI; ANTUNES, 2001). 
O albúmen exerce influência na qualidade do ovo, controlando a posição da gema no ovo intacto. A posição e o movimento da gema são indicações importantes da qualidade interna do ovo. Dentro do ovo intacto, o albúmen consiste de camadas concêntricas de gel incolor e líquido. Quando um ovo fresco é cuidadosamente quebrado em uma superfície homogênea e plana, a gema está túrgida e localizada centralmente, circundada pelo albúmen denso e delgado. Por sua vez, quando um ovo velho é quebrado, a gema está flácida, frequentemente localizada em um lado, e circundada por uma área ampla de líquido (OLIVEIRA, 2006).

0 armazenamento tem papel fundamental na conservação dos ovos, pois é durante esse período que ocorrem alterações de origem física, química e microbiana. Portanto, o tempo e a temperatura devem estar ligados a outros fatores para garantir boa preservação. 0 emprego de tecnologia adequada logo após a postura é necessário para prolongar a vida útil do ovo e seus produtos derivados. 0 armazenamento do ovo fresco deve ser cuidadoso, em virtude das perdas que ocorrem em qualidade, principalmente pelo crescimento microbiano, perdas de peso e todos os processos de desintegração químicos e físicos, que têm influência adversa sobre o estado original de frescor e sobre a palatabilidade (SOUZA-SOARES; SIEWERDT, 2005).

O objetivo deste trabalho foi avaliar a qualidade interna de ovos vermelhos de galinha de granja comercial e tipo caipira comercializados em supermercados, mercados de bairro e na feira livre da cidade de Barreiras, Bahia. Esses ovos foram submetidos a diferentes condições de temperatura de armazenagem, e sua qualidade foi analisada utilizando-se como parâmetros o peso médio do ovo, a altura de albúmen, a unidade Haugh e o percentual do albúmen e da gema.

\section{Materiais e métodos}

0 experimento seguiu esquema fatorial $3^{3}$ (estabelecimento comercial x local de armazenagem doméstica), segundo delineamento inteiramente casualizado, com medidas repetidas no tempo.

Ovos vermelhos de granja comercial e tipo caipira, comercializados na cidade de Barreiras, Bahia, foram adquiridos em supermercados, mercadinhos e feira livre, durante quatro semanas consecutivas, entre fevereiro e março de 2009. Semanalmente, foram adquiridos 60 ovos tipo grande aos sábados, simulando o consumidor padrão, sendo 24 ovos provenientes de granja comercial adquiridos em dois supermercados, 24 ovos provenientes de granja comercial adquiridos em dois mercadinhos e 12 ovos tipo caipira adquiridos na feira livre da cidade de Barreiras.

Os ovos adquiridos nos dois supermercados, localizados no centro da cidade, eram apresentados em embalagem, na qual constava a data de validade do produto. Por outro lado, os ovos coletados nos mercadinhos estavam acomodados em bandejas abertas de papelão, com ausência de informações sobre data de embalagem e validade. Esses tipos de ovos foram comprados em diferentes mercadinhos (A e B) a cada semana, abrangendo quatro bairros periféricos da cidade de Barreiras. Na feira livre, os ovos eram comercializados em sacos plásticos com período entre um e cinco dias após a postura, segundo informação do comerciante. Todos os ovos caipiras foram provenientes do mesmo feirante. Não foi possível mensurar o intervalo entre a postura e a data de compra nos mercadinhos e na feira livre, em razão da ausência de informações na embalagem. Nos supermercados, os ovos foram adquiridos dentro do período de validade.

As avaliações de peso médio do ovo, altura de albúmen, unidade Haugh, porcentagem do albúmen e da gema foram realizadas no Laboratório do Núcleo de Estudo e Pesquisa em Produção Animal, Faculdade de Agronomia da Universidade do Estado da Bahia (UNEB), Câmpus IX, Barreiras, Bahia.

No laboratório, 6 dos 12 ovos de cada estabelecimento comercial foram selecionados aleatoriamente e pesados em balança com duas casas decimais. Quatro dos seis ovos foram utilizados para medir a altura do albúmen espesso em uma superfície plana de vidro, com o auxílio de um paquímetro digital. Com base nesses dados, foi calculada a unidade Haugh, que é a relação entre a altura do albúmen e o peso do ovo: $100 \log \left(\mathrm{H}+7,57-1,7 \mathrm{~W}^{0,37}\right)$, onde $\mathrm{H}=$ altura do albúmen e $\mathrm{W}=$ peso do ovo. Essa análise foi realizada no mesmo dia de aquisição. Os outros dois dos seis ovos de cada estabelecimento foram usados para a quantificação da relação entre albúmen e gema, quebrando o ovo cuidadosamente e separando a gema do albúmen em um separador próprio para essa finalidade. 0 albúmen e a gema 
foram colocados em um béquer e seus pesos relativos foram calculados em percentual.

Trinta ovos foram separados semanalmente, sendo seis do supermercado A, seis do supermercado B, seis do mercadinho A, seis do mercadinho B e seis da feira livre (tipo caipira). Então, dois ovos de cada grupo foram armazenados na porta e dois no fundo de um refrigerador doméstico de $280 \mathrm{~L}$, manipulado normalmente em uma casa com quatro moradores. Os outros dois restantes de cada grupo foram mantidos sob temperatura ambiente. A temperatura e a umidade relativa do ar foram monitoradas diariamente com o auxílio de um termo-higrômetro digital. A temperatura e a umidade relativa do ar médias no período de armazenamento foram de $15,7{ }^{\circ} \mathrm{C}, 67 \% ; 12,4{ }^{\circ} \mathrm{C}, 69 \%$ e $28,4{ }^{\circ} \mathrm{C}, 68 \%$, respectivamente, para porta, fundo e fora do refrigerador (temperatura ambiente).

Metade desses ovos foi analisada quanto à qualidade interna, indicada pela unidade Haugh, com sete dias, e o restante com 14 dias de armazenagem.

Os dados foram tabulados no programa Excel e submetidos à análise de variância segundo delineamento inteiramente casualizado com o uso do programa Assistat e teste de Tukey para a comparação de médias, com desdobramento das interações significativas, considerando-se como significativos os valores da probabilidade do valor de F menor que 5\% ( $p<0,05)$.

\section{Resultados e discussão}

0 peso dos ovos não diferiu $(p>0,05)$ entre os pontos de venda no supermercado e no mercadinho popular (Tabela 1). Ambos estavam dentro do padrão para a categoria dos ovos em estudo, tipo grande (ovos com peso mínimo de 55 g), conforme estabelecido pela legislação brasileira (MAPA, 1990). Contudo, constatou-se diferença $(\mathrm{p}<0,05)$ entre os estabelecimentos citados e a feira livre, a qual apresentou a menor média para peso dos ovos. Na feira livre, os ovos analisados foram do tipo caipira que, em geral, apresentam menor peso. Segundo Barbosa et al. (2007), os ovos das galinhas caipiras embora não obedeçam a um padrão de dimensão, coloração da casca e peso - em virtude da grande diversidade genética das aves, também se diferenciam dos ovos de sistemas altamente tecnificados por sabor, consistência e coloração da gema.
Os valores encontrados para peso dos ovos nos supermercados e mercadinhos (Tabela 1) foram semelhantes aos verificados por Leandro et al. (2005), e a média foi um pouco superior à observada por Oliveira et al. (2001). A altura do albúmen não diferiu estatisticamente $(\mathrm{p}>0,05)$ entre os ovos dos três tipos de estabelecimentos comerciais, originando a média de 4,53 mm. Ovos após a postura apresentam maior altura de albúmen e, consequentemente, maior unidade Haugh; portanto, melhor qualidade, uma vez que a fluidificação do albúmen é um sinal de perda da qualidade (JONES; MUSGROVE, 2005).

Com relação à percentagem de albúmen, houve diferença significativa $(\mathrm{p}<0,05)$ entre os tratamentos no supermercado e na feira livre. Os ovos adquiridos em supermercados apresentaram o maior percentual de albúmen, seguidos dos ovos de mercadinhos; os ovos de feira indicaram o menor percentual de albúmen (Tabela 1). Por outro lado, a percentagem de gema entre os tratamentos apresentou relação inversa à de albúmen, para a qual a feira livre apresentou o maior percentual de gema, diferindo significativamente $(\mathrm{p}<0,05)$ do percentual de gema em ovos dos supermercados. Os mercadinhos apresentaram valores intermediários.

Com base na qualidade interna e externa de ovos comercializados em supermercados e feiras livres de Imperatriz (MA), Pascoal et al. (2008) encontraram incompatibilidade entre o padrão de qualidade da categoria dos ovos indicada na embalagem e os resultados apresentados na pesquisa. Segundo esses autores, os ovos comercializados diretamente na granja apresentaram melhor qualidade.

A unidade Haugh foi mais elevada nos ovos da feira livre $(67,84)$ e dos supermercados $(64,5)$ do que nos mercadinhos populares $(51,5)$ (Tabela 1). Esses resultados mostram que os ovos comercializados em supermercados e nas feiras livres eram provavelmente mais frescos, ou seja, apresentavam menor período de armazenamento após a postura quando comparados aos ovos de mercadinho. Os valores de unidade Haugh obtidos neste trabalho foram bem inferiores aos valores (98) observados por Oliveira et al. (2001) em ovos analisados no dia da postura.

De acordo com Moreng e Avens (1990), as enzimas presentes no albúmen hidrolisam as cadeias de aminoácidos ao destruírem a estrutura proteica e liberarem água ligada a grandes moléculas de proteínas, o que provoca a fluidificação do albúmen e a perda da 
Tabela 1 - Médias de peso do ovo, altura e percentagem de albúmen e da gema e unidade Haugh de ovos comercializados em Barreiras (BA)

\begin{tabular}{lccccc}
\hline Ponto de venda & Peso do ovo (g) & Altura do albúmen $(\mathbf{m m})$ & \% de albúmen & \% de gema & Unidade Haugh \\
\cline { 2 - 6 } Grandes supermercados & $59,5^{\mathrm{a}}$ & $4,81^{\mathrm{a}}$ & $60,7^{\mathrm{a}}$ & $25,6^{\mathrm{b}}$ & $64,5^{\mathrm{ab}}$ \\
Mercadinhos populares & $62,6^{\mathrm{a}}$ & $4,15^{\mathrm{a}}$ & $59,1^{\mathrm{ab}}$ & $26,9^{\mathrm{ab}}$ & $51,5^{\mathrm{b}}$ \\
Feira livre & $51,3^{\mathrm{b}}$ & $4,64^{\mathrm{a}}$ & $56,7^{\mathrm{b}}$ & $29,7^{\mathrm{a}}$ & $67,8^{\mathrm{a}}$ \\
DMS $^{* *}$ & 6,28 & 2,05 & 3,66 & 4,04 & 16,3 \\
${\text { C.V. }(\%)^{* *}}$ & 5,50 & 22,9 & 3,15 & 7,47 & 13,5 \\
\hline
\end{tabular}

Fonte: Dados da pesquisa.

Legenda: ${ }^{*}=$ Letras diferentes na mesma coluna diferem estatisticamente entre si $(p<0,05) ;{ }^{* *}$ DMS = diferença mínima significativa; C.V. $=$ coeficiente de variação.

viscosidade do albúmen mais denso. Esse processo é dependente do período e da temperatura de armazenamento, com maior velocidade durante os primeiros dias após a postura (JONES; MUSGROVE, 2005).

Os resultados da unidade Haugh dos ovos comercializados não apresentaram interação significativa $(p>0,05)$ entre os fatores (estabelecimento comercial $x$ local de armazenagem $x$ dia de armazenamento). No entanto, as médias diferiram entre os locais de armazenagem e os estabelecimentos comerciais, para os diferentes dias de armazenamento (7 e 14 dias), (Gráfico 1).

Com sete dias de armazenagem, os ovos vermelhos adquiridos em supermercados e os ovos tipo caipira obtidos na feira não diferiram quanto à qualidade interna, indicada pela unidade Haugh, enquanto os valores dos ovos de mercadinhos populares apresentaram diferenças significativas quando armazenados em temperatura ambiente (Gráfico 1a). Entretanto, com 14 dias de armazenagem, houve declínio significativo $(\mathrm{p}<0,05)$ da qualidade dos ovos vermelhos, tanto dos adquiridos em supermercados quanto em mercadinhos, quando mantidos sob temperatura ambiente (Gráfico 1b).

Seleim e El-Prince (2000) mostraram que ovos estocados por 15 dias em ambiente natural perderam qualidade interna, demonstrada pela liquefação do albúmen e o enfraquecimento da membrana vitelínica.

A diminuição nos valores da unidade Haugh representa declínio na qualidade do ovo. Morais et al. (1997) observaram redução nos valores médios da unidade Haugh, de 77,2 para 53,5 (30,7\%), em sete dias de armazenamento, com a temperatura variando de 18 a $29^{\circ} \mathrm{C}$, em estabelecimentos atacadistas e varejistas da região de Uberlândia (MG).
A temperatura recomendada para o armazenamento de ovo fresco é de 8 a $15{ }^{\circ} \mathrm{C}$, com umidade relativa do ar entre 70 e $90 \%$. Quando o armazenamento ultrapassa 30 dias, recomendam-se temperaturas entre 4 e $12{ }^{\circ} \mathrm{C}$, ou em torno de $0{ }^{\circ} \mathrm{C}$. Para longos períodos, a umidade relativa deve estar entre 70 e $80 \%$ (BRASIL, 1990).

Morais et al. (1997) analisaram, durante sete dias, a qualidade de ovos armazenados em temperatura ambiente, distribuídos em hipermercado, supermercado atacadista e mercadinhos populares. Ocorreu uma redução durante o armazenamento nos valores médios de unidades Haugh encontrados para ovos frescos independentemente do tipo de estabelecimento. No entanto, no supermercado popular, esses valores foram menores que aqueles do supermercado atacadista e do hipermercado, sendo esta diferença associada às condições de armazenamento (temperatura e umidade) de cada estabelecimento.

De acordo com os resultados obtidos neste estudo e na literatura, observou-se que a temperatura de armazenamento influencia consideravelmente os valores de unidades Haugh; todavia, a resposta dos ovos caipiras adquiridos na feira livre foi diferente, sendo que em até 14 dias não houve alteração significativa na qualidade em virtude do local de armazenagem residencial.

Métodos que aumentem a vida de prateleira dos ovos após a postura seriam interessantes para a cadeia produtiva da avicultura de postura. Pombo et al. (2006) concluíram que o tratamento térmico de ovos à temperatura de $57^{\circ} \mathrm{C}$ por 20 minutos proporcionou aumento da estabilidade nas características de qualidade interna, podendo ser um método interessante às indústrias de ovos que primam pela manutenção 


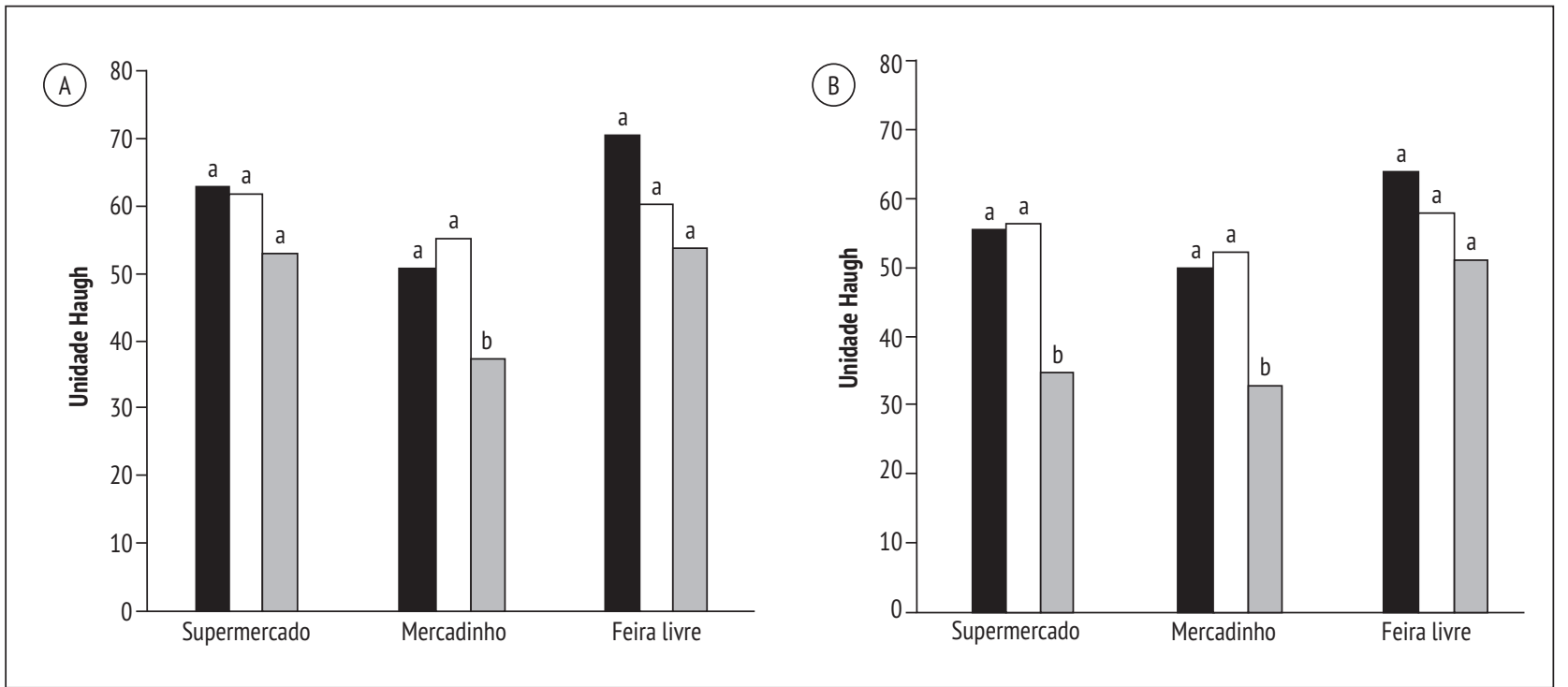

Gráfico 1 - Valores médios de unidade Haugh de ovos obtidos em diferentes comércios varejistas e conservados no fundo ( $\square$ ) e na porta ( $\square$ ) de refrigerador doméstico e em temperatura ambiente ( $\square$ ) após 7 (a) e 14 (b) dias de armazenamento

Fonte: Dados da pesquisa.

Legenda: ${ }^{*}=$ Letras diferentes na mesma coluna diferem estatisticamente $(p<0,05)$.

da qualidade dos produtos oferecidos à população. Em geral, as pessoas adquirem ovos, principalmente nos supermercados, nas condições de temperatura ambiente (RODRIGUES; SALAY, 2001).

Os ovos comercializados em Barreiras (BA), comprados nos supermercados e na feira livre, apresentam qualidade intermediária, enquanto os do mercadinho apresentaram baixa qualidade segundo a classificação do Departamento de Agricultura dos Estados Unidos. A exigência de refrigeração dos ovos (temperatura de $5{ }^{\circ} \mathrm{C}$ ) logo após a postura e sua manutenção na cadeia de distribuição são garantidas por lei para a comercialização de ovos em alguns países, como os Estados Unidos.

A escolha do local de aquisição e a maneira doméstica de conservação dos ovos são critérios importantes a serem levados em consideração pelo consumidor.

\section{Conclusão}

A partir dos dados do presente estudo, concluiu-se que os melhores estabelecimentos para a aquisição de ovos são os supermercados e a feira livre (ovos caipiras), permanecendo os mercadinhos como os menos indicados. Além disso, o ambiente refrigerado apresentou-se como o melhor local para armazenagem de ovos por maiores períodos de tempo, tanto na porta quanto no fundo da geladeira.

\section{Referências}

ALLEONI, A. C. C.; ANTUNES, A. J. Unidade Haugh como medida da qualidade de ovos de galinha armazenados sob refrigeração. Scientia Agrícola, v. 58, n. 4, p. 681685,2001

AUSTIC, R. E.; NESHEIM, M. C. Poultry production. London: Lea Febiger, 1990.

BARBOSA, F. J. V. et al. Sistema alternativo de criação de galinhas. 2007. Disponível em: <http://sistemas deproducao.cnptia.embrapa.br/FontesHTML/Ave/ SistemaAlternativoCriacaoGalinhaCaipira/Comercializacao.htm>. Acesso em: 23 set. 2011.

BERTECHINI, G. A. Mitos e verdades sobre o ovo de consumo. In: CONFERÊNCIA APINCO DE CIÊNCIA E TECNOLOGIA AVÍCOLAS, 1., 2003, Campinas. Anais... Campinas: FACTA, 2003. p. 19-26.

EISEN, E. J. et al. The Haugh unit as a measure of egg albumen quality. Poultry Science, v. 41, p. 1461-1468, 1962. 
HAUGH, R. R. The Haugh unit for measuring egg quality. United States Egg Poultry Magazine, v. 43, p. 552-555, 1937.

HEIMAN, V.; CARVER, J. S. The albumen index as a physical measurement of observed egg quality. Poultry Science, v. 15, p. 141-148, 1936.

HOLTS, W. F.; ALMQUIST, H. J. Measurement of deterioration in the stored hen's egg. United States Egg Poultry Magazine, v. 38, p. 70, 1932.

JONES, D. R.; MUSGROVE, M. T. Effects of extended storage on egg quality factors. Poultry Science, v. 84, p. 17741777, 2005.

LEANDRO, N. S. M. et al. Aspectos de qualidade interna e externa de ovos comercializados em diferentes estabelecimentos na região de Goiânia. Ciência Animal Brasileira, v. 6, n. 2, p. 71-78, 2005.

BRASIL. Ministério de Agricultura, Pecuária e Abastecimento - MAPA. Portaria n. 1, de 21 de fevereiro de 1990. Normas Gerais de Inspeção de Ovos e Derivados, Ministério da Agricultura, Pecuária e Abastecimento, 1990. Disponível em: <http://www.cidasc. sc.gov.br/html/servico_animal/Inspecao\%20Animal/ ORIENTA\%C7\%D5ES\%20SOBRE\%20ROTULAGEM/ OVOS\%20E\%20DERIVADOS/PORTARIA\%20MAPA\%20 01_90_normas $\% 20$ gerais $\% 20$ inspe $\%$ E7\%E3o\% 20 ovos\%20e\%20derivados.pdf>. Acesso em: 23 set. 2011.

MORAIS, C. F. A. et al. Qualidade interna de ovos comercializados em diferentes supermercados na cidade de Uberlândia. Arquivo Brasileiro de Medicina Veterinária e Zootecnia, v. 49, p. 365-373, 1997.

MORENG, R. E.; AVENS, J. S. Ciência e produção de aves. São Paulo: Roca, 1990.

OLIVEIRA, C. A. F. et al. Produção e qualidade dos ovos de poedeiras submetidas à intoxicação prolongada com aflatoxina $\mathrm{B}_{1}$. Arquivos do Instituto Biológico, v. 68, n. 2, p. 1-4, 2001.

OLIVEIRA, G. E. Influência da temperatura de armazenamento nas características físico-químicas e nos teores de aminas bioativas em ovos. Belo Horizonte, Minas Gerais. 2006. 78 f. Dissertação (Mestrado em Farmácia) - Universidade Federal de Minas Gerais, 2006.

PARSONS, C. H.; MINK, L. D. Correlation of methods for measuring the interior quality of eggs. United States Egg Poultry Magazine, v. 43, p. 484-489, 1937.
PASCOAL, L. A. F. et al. Qualidade de ovos comercializados em diferentes estabelecimentos na cidade de ImperatrizMA. Revista Brasileira de Saúde e Produção Animal, v. 9, n. 1, p. 150-157, 2008.

POMBO, C. R. et al. Efeito do termoprocessamento sobre o peso e a qualidade interna de ovos inteiros. Revista Brasileira de Ciência Veterinária, v. 13, n. 3, p. 183-185, 2006.

RODRIGUES, K. R. M.; SALAY, E. Atitudes de granjeiros, atacadistas, varejistas e consumidores em relação à qualidade sanitária do ovo de galinha in natura. Revista de Nutrição, v. 14, n. 3, p. 185-193, 2001.

ROSSI, M.; POMPEI, C. Changes in some egg components and analytical values due to hen age. Poultry Science, v. 74, p. 152-160, 1995.

SELEIM, M. A.; EL-PRINCE, E. Effect of storage and boiling on some quality characteristics of eggs. Assiut Journal of Agricultural Sciences, v. 31, n. 4, p. 1-15, 2000.

SMITH, M. B.; NGUYEN, L. Measuring the age of stored eggs. Food Research Quarterly, v. 44, p. 94-96, 1984.

SOUZA-SOARES, L. A.; SIEWERDT, F. Aves e ovos. Pelotas: Editora da Universidade UFPEL, 2005.

WILGUS, H. S.; WAGENEN, A. V. The height of the firm albumen as a measure of its condition. Poultry Science, v. 15, p. 319-321, 1936.

WILLIAMS, K. C. Some factors affecting albumenn quality with particular reference to Haugh unit score. World's Poultry Science Journal, v. 48, p. 5-16, 1992.

Recebido: 21/07/2011 Received: 07/21/2011

Aprovado: 10/11/2011 Approved: 11/10/2011 